\title{
In vitro expression of the HIV-2 genomic RNA is controlled by three distinct internal ribosome entry segments that are regulated by the HIV protease and the Gag polyprotein
}

\author{
EMILIANO P. RICCI, ${ }^{1,2,4}$ CÉCILE H. HERBRETEAU, ${ }^{1,2,4}$ DIDIER DECIMO, ${ }^{1,2}$ ANDREAS SCHAUPP, ${ }^{1,2}$ \\ SIDDHARTHA A.K. DATTA, ${ }^{3}$ ALAN REIN, ${ }^{3}$ JEAN-LUC DARLIX, ${ }^{1,2}$ and THÉOPHILE OHLMANN ${ }^{1,2}$ \\ ${ }^{1}$ Ecole Normale Supérieure de Lyon, Unité de Virologie Humaine, IFR 128, Lyon F-69364, France \\ ${ }^{2}$ Inserm, U758, Lyon F-69364, France \\ ${ }^{3}$ HIV Drug Resistant Program, National Cancer Institute, Frederick, Maryland 21702-1201, USA
}

\begin{abstract}
The HIV-2 genomic RNA serves both as a messenger for protein synthesis and as a genome for viral assembly and particle production. Our previous work has shown that the HIV-2 genomic RNA encodes two additional Gag proteins that are Nterminal truncated isoforms of the p57 Gag polyprotein. In this study, by the use of mono- and bicistronic RNAs we show that translation at the three AUGs is driven by three distinct and independent internal ribosome entry segments both in vitro and ex vivo. Furthermore we used the recombinant Gag and HIV-2 protease to show that, in vitro, translation is tightly regulated by these two viral proteins. This regulation is exerted both at the level of protein production and also on the selection of the AUG initiation site which changes the ratio at which the three different Gag isoforms are produced.
\end{abstract}

Keywords: HIV; translation initiation; Gag; IRES; HIV protease

\section{INTRODUCTION}

In eukaryotic cells, gene expression is controlled from the early stage of RNA synthesis up to translation in the cytoplasm (Gale et al. 2000). For the majority of eukaryotic mRNAs, translation begins by the attachment of the $40 \mathrm{~S}$ ribosomal subunit to the $5^{\prime}$-capped end of the transcript followed by linear scanning until it reaches an initiation codon in a good nucleotide context (Kozak 1989). This process is mediated by a number of proteins called initiation factors that allow both efficient binding of the ribosome to the mRNA and migration to the initiation codon. Among them, the eIF4F complex composed of eIF4E, eIF4A, and eIF $4 \mathrm{G}$ plays a critical role both in promoting ribosomal entry onto the mRNA and scanning of the preinitiation complex (Gingras et al. 1999). eIF4E is a $26 \mathrm{kDa}$ phosphoprotein whose function is to bind to the $5^{\prime}$-end cap structure of the eukaryotic mRNA in order to direct the assembly of the

\footnotetext{
${ }^{4}$ These authors contributed equally to this work.

Reprint requests to: Théophile Ohlmann, Ecole Normale Supérieure de Lyon, Unité de Virologie Humaine, IFR 128, Lyon F-69364, France; e-mail: tohlmann@ens-lyon.fr; fax: (33) 472-728-137.

Article published online ahead of print. Article and publication date are at http://www.rnajournal.org/cgi/doi/10.1261/rna.813608.
}

preinitiation complex; eIF4A is an RNA helicase that has the ability to unwind short RNA duplexes in an ATP dependent manner. Finally, the eIF4G initiation factor is the scaffold protein for eIF4E, eIF4A, and the poly(A) binding protein (PABP) (Prevot et al. 2003a).

In 1988, the study of picornaviral RNA translation led to the characterization of an alternative mechanism of translation initiation by direct ribosome binding to the $5^{\prime}$-UTR (Jang et al. 1988; Pelletier and Sonenberg 1988). This is rendered possible by an RNA domain called the internal ribosome entry segment (IRES), which enables efficient translation independently from the $5^{\prime}$-capped end of the mRNA (Jackson et al. 1994). During this process, the $40 \mathrm{~S}$ ribosomal subunit associated with initiation factors in the form of a $43 \mathrm{~S}$ preinitiation complex binds to the IRES located upstream of the AUG initiation site (Vagner et al. 2001; Stoneley and Willis 2004). In many instances, this mechanism was shown to be mediated by the IRES threedimensional (3D) structure (Yaman et al. 2003; Otto and Puglisi 2004; Spahn et al. 2004).

Although a large number of IRES sequences of viral and cellular origins have now been identified, a structural model for IRES activity has not yet emerged suggesting that there is not one but several RNA motifs that enable ribosomal 
entry (Bonnal et al. 2003). In agreement with this idea, there is a broad diversity of nonrelated genes that use internal ribosome entry (Vagner et al. 2001).

IRES elements have now been identified within the simian immunodeficiency virus (SIV) and the human immunodeficiency virus type I (HIV-1) (Ohlmann et al. 2000; Buck et al. 2001; Waysbort et al. 2001; Brasey et al. 2003), HIV-2 (Herbreteau et al. 2005), and more recently, feline immunodeficiency virus (FIV) (Camerini et al. 2008) members of the lentivirus family, suggesting that translation of the retroviral genomic RNA is tightly controlled (Balvay et al. 2007). The human immunodeficiency virus type 2 is a member of the lentivirus group of retroviruses and is, with HIV-1, the etiological agent of AIDS in humans (Bock and Markovitz 2001). Although HIV-2 and HIV-1 share a common genetic organization, HIV-2 is more closely related to simian immunodeficiency viruses (Lemey et al. 2003).

The full-length genomic RNA of HIV-2 serves both as genome for the production of new virions and as messenger RNA for the synthesis of Gag and Gag-Pol precursors during the late step of viral replication (Butsch and BorisLawrie 2002). The HIV-2 genomic RNA has a 548-nucleotide (nt)-long 5'-UTR, which harbors several RNA motifs necessary for genome dimerization and packaging (Reeves and Doms 2002). These motifs are the preferential binding sites for the neo-synthesized Gag proteins thus forming an RNA-Gag complex that creates a scaffold for multimerization of additional Gag molecules. Building such a complex ultimately results in selection of the genomic RNA for encapsidation and viral assembly.

Our previous work has shown that the HIV-2 genomic RNA codes for the wild-type (WT) p57 Gag protein and two additional $\mathrm{N}$ truncated Gag isoforms that are produced by internal entry of the ribosomes from the coding region. However, the translational mechanism by which ribosomes can be displayed to three distinct initiation sites was not further investigated.

By using mono- and bicistronic constructs together with antisense 2'-O-methyloligoribonucleotides, we now show that three independent IRES are located within the HIV-2 gag coding region. These sequences have the ability to drive translation initiation at each of the three AUG initiation codons. Further investigation into this complex mechanism of ribosomal entry reveals that selection of the initiation site is mainly influenced by two virally encoded proteins, namely, the protease and the Gag polyprotein.

\section{RESULTS}

\section{Gag translation is driven by three IRES located within the coding region}

We have previously shown that translation of the HIV-2 genomic RNA from the authentic AUG1 site (producing p57) occurs by internal entry of the ribosomes on an IRES sequence which has the unique ability to load ribosomes upstream of its core sequence (Herbreteau et al. 2005). This is rendered possible by a region of 50 nucleotides located just downstream from the first AUG (position +548) that forms a long range RNA interaction and was shown to be critical for initiation at the authentic initiation site (Herbreteau et al. 2005). However, the mechanism by which initiating ribosomes are able to access the two other downstream AUG sites (positions +746 and +899 ) remained to be determined as well as the role of the $5^{\prime}$-UTR in the overall translation mechanism of the wild type genomic RNA.

Thus, we have constructed a series of bicistronic RNAs that is depicted in Figure 1A, and which contains the neomycin gene as the first cap-dependent cistron and harbors the LacZ gene as the second cistron. Various regions of the HIV-2 genomic RNA including the 5'-UTR, the coding region encompassing AUG1 to AUG3, or a series of deletions, were inserted in the bicistronic RNA and translated in the rabbit reticulocyte lysate. As shown previously (Herbreteau et al. 2005), the 5'-UTR alone led to poor expression of the LacZ gene (Fig. 1B, lane 1) whereas

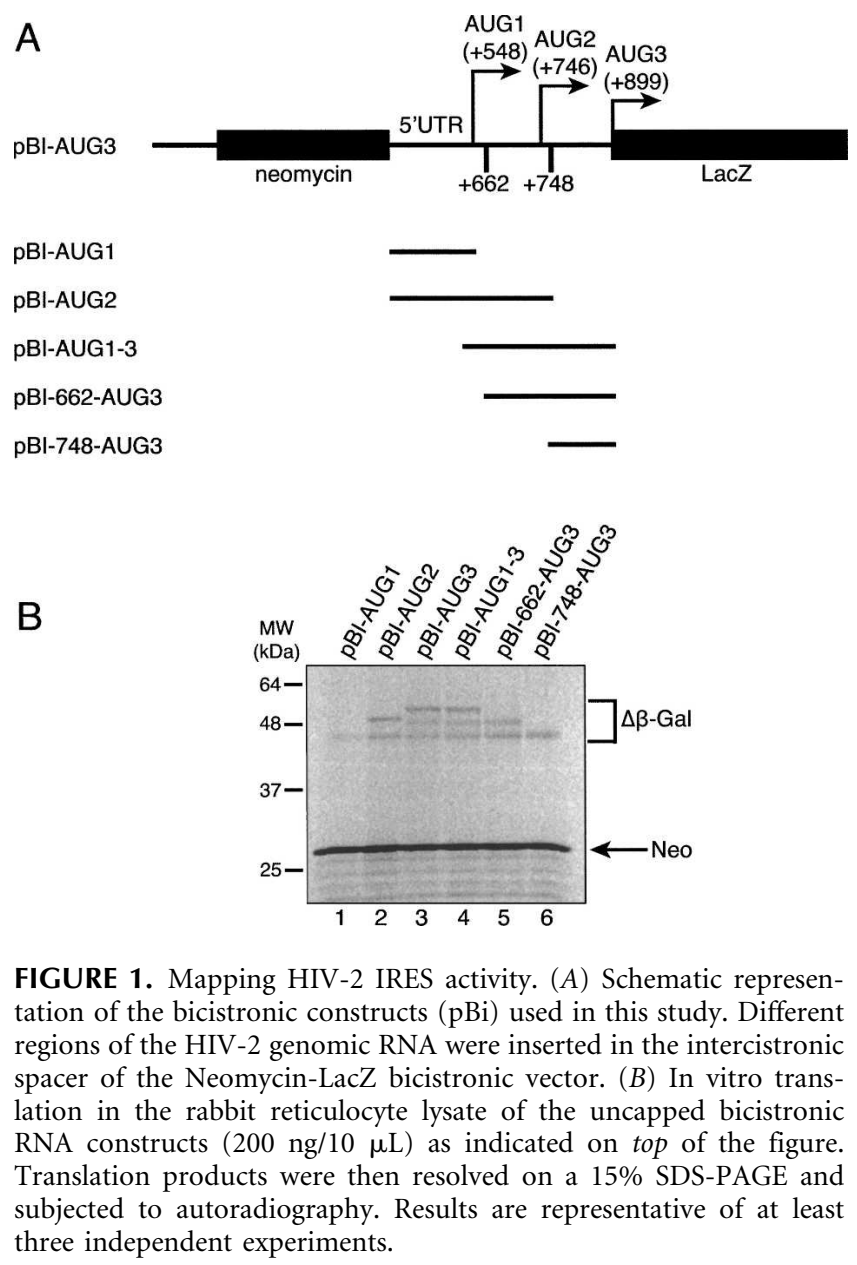


efficient translation of the three $\beta-G a l$ isoforms was observed when the $5^{\prime}$-UTR was followed by segments of the gag coding region spanning from AUG1 to AUG3 (Fig. 1B, lanes 2,3). Moreover, complete removal of the $5^{\prime}$-UTR did not affect IRES activity in agreement with our previous findings (Fig. 1B, lane 4; Herbreteau et al. 2005). Internal deletions within the gag coding region were then generated in the context of the bicistronic construct. Interestingly, 5' deletions starting some 114 nucleotides downstream from the AUG1 site did not impair translation initiation at AUG2 and AUG3 (Fig. 1B, lane 5). Moreover, a further $5^{\prime}$ deletion starting downstream from AUG2 did not affect translation at the third AUG site (Fig. 1B, lane 6).

In order to confirm the in vitro results, capped and polyadenylated bicistronics RNAs containing either the entire Gag coding region from AUG1 to AUG3 or a series of 5 'deletions between the Firefly and the Renilla luciferase coding region (Fig. 2A) were transfected in HeLa cells. As expected, the empty vector was poorly translated (Fig. 2C, "pFR-NoIRES"). Activity of bicistronics RNAs containing the entire Gag coding region or $5^{\prime}$ deletions (Fig. 2C) was also quite low but was still twofold to fourfold above the negative control. It should be noted that luciferase activity driven by monocistronic capped and polyadenylated RNAs containing the HIV-2 coding region was also very low (data not shown). We have expressed the $2 \mathrm{~A}$ protease from poliovirus in HeLa cells to cleave eIF4G. Proteolysis of eIF4G by this protease inhibits capdependent translation whereas IRES-driven translation is maintained or stimulated (Ziegler et al. 1995; Ohlmann et al. 1997). Upon eIF4G cleavage by the virally encoded protease 2A (Fig. 2B), translation of the Renilla luciferase driven by the HIV-2 Gag coding region, or segments of it, was highly stimulated compared to the negative control (Fig. 2C). Interestingly, as observed in vitro, 5' deletions of the Gag coding region starting downstream from AUG1 (pFR-662AUG3) or downstream from AUG2 (pFR-748-AUG3) showed translational activities comparable to that of the entire Gag coding region (pFR-AUG1-3) (Fig. 2C). These data indicate that translation initiation occurs independently at each of the three AUG initiation sites both in vitro and ex vivo suggesting the presence of three distinct and independent IRES elements. experiments.
B

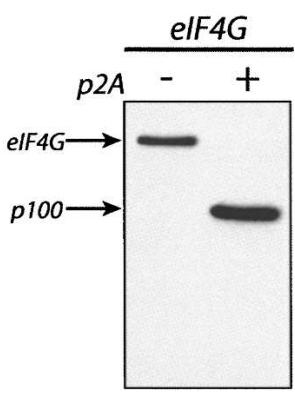

PFR-NOIRES pFR-AUG1-3 pFR-662-AUG3 PFR-748-AUG3

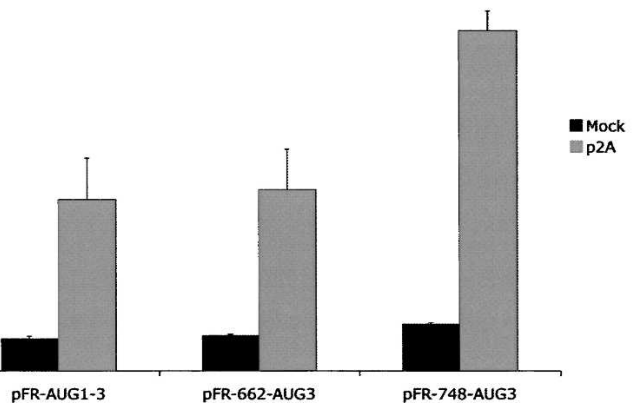
PFR-AUG1-3 PFR-662-AUG3 bicistronic constructs (pFR) used in this study. Different regions of the HIV-2 genomic RNA were inserted in the intercistronic spacer of the firefly-Renilla bicistronic vector (see Materials coding biciter from poliovirus. (C) Transfection of capped and polyadenylated (Mock) with an RNA coding for the $\mathrm{p} 2 \mathrm{~A}$ protease. Luciferase activities were measured $3 \mathrm{~h}$ posttransfection. R/F ratios were calculated and normalized to the value of the pFR-NoIRES

In order to confirm that internal initiation takes place at each of the three AUG initiation sites from monocistronic RNAs in vitro, we have used the L-protease from foot-and-mouth disease virus (FMDV) that also cleaves eIF4G. Thus, the RRL was pre-incubated for $10 \mathrm{~min}$ with increasing concentrations of in vitro generated L-protease in order to cleave eIF4G (see Supplemental Fig. 1). Then, the RRL was programmed with a set of different control RNAs in which the LacZ coding region is driven by the capped 5'-UTR of globin (Fig. 3, lanes 1-3) or the uncapped IRES of EMCV (Fig. 3, lanes 4-6). Capped and uncapped wild-type HIV-2 genomic RNA (Fig. 3, T7-WT HIV-2, lanes 7-12) and the HIV-2 genomic RNA devoided of its $5^{\prime}$-UTR and commencing directly at AUG1 (Fig. 3, T7-AUG1 HIV-2, lanes 13-18) were also translated in the RRL treated by the L-protease. As expected, cap-dependent Globin-LacZ translation was strongly inhibited by addition 

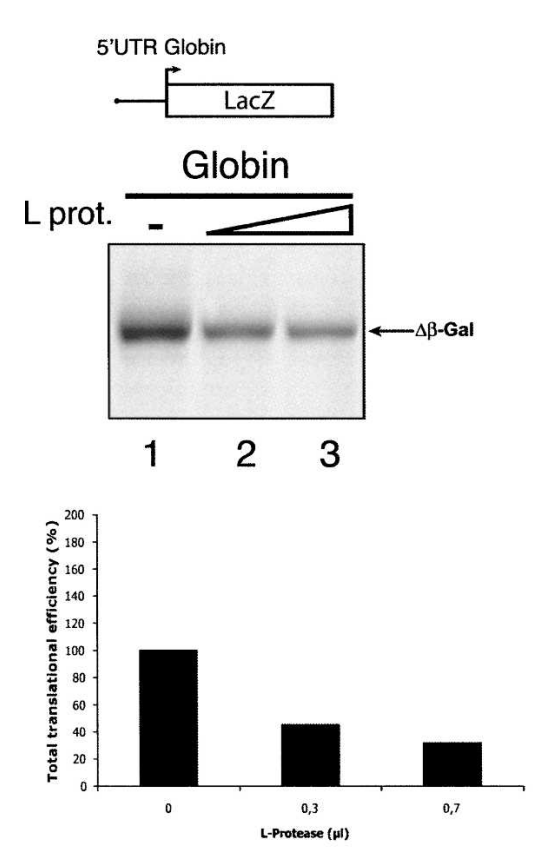

T7-WT HIV-2
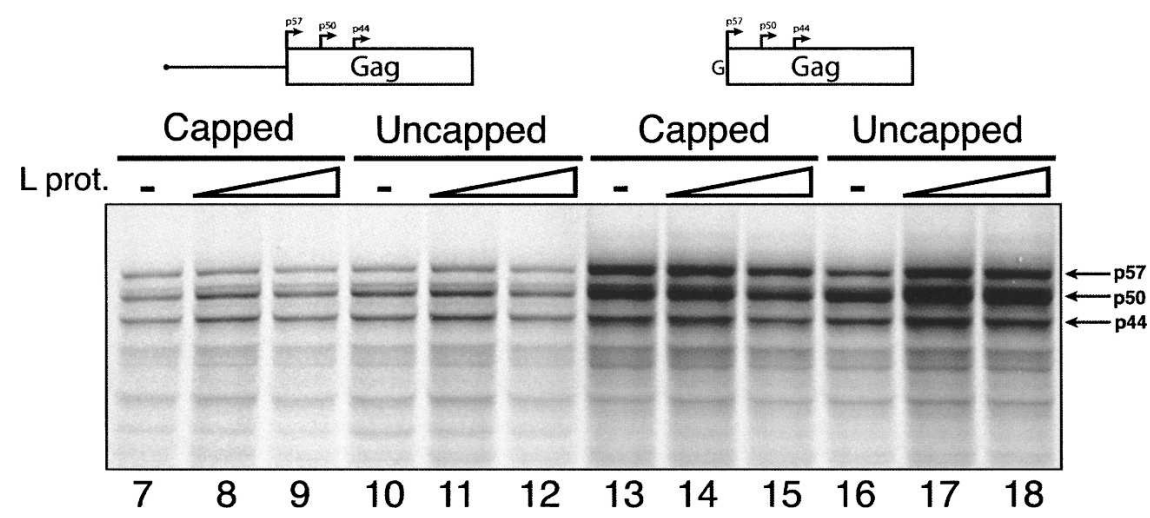

FIGURE 3. Cleavage of eIF4G stimulates HIV-2 translation. A RRL under full translation conditions was preincubated for $10 \mathrm{~min}$ without (lanes $1,4,7,10,13,16$ ) or with $0.3 \mu \mathrm{L}$ (lanes $2,5,8,11,14,17$ ) or $0.7 \mu \mathrm{L}$ (lanes $3,6,9,12,15,18)$ of in vitro produced FMDV L-protease. GlobinLacZ (15 ng/10 $\mu \mathrm{L})$, EMCV-LacZ (184 ng/10 $\mu \mathrm{L})$, T7-WT (200 ng/10 $\mu \mathrm{L})$, and T7-AUG1 (35 $\mathrm{ng} / 10 \mu \mathrm{L}$ ) were translated as indicated on the figure and the resulting products resolved on a $13 \%$ SDS-PAGE and submitted to autoradiography. The relative intensities of the bands were quantified using a storm 850 phosphoimager and expressed as arbitrary units presented at the bottom of each panel. T7-WT and T7-AUG1 overall translation was quantified by the addition of the activities of each of the Gag isoforms. Results are representative of at least three independent experiments.

of the protease in a dose-dependent manner (Fig. 3, lanes 2,3) whereas EMCV IRES-driven translation was stimulated (Fig. 3, lanes 4-6). Interestingly, production of the three Gag isoforms p57, p50, and p44 from the wild-type RNA was not diminished by the addition of the L-protease whether this mRNA was capped or uncapped (Fig. 3, lanes 7-12). Translation of the leaderless HIV-2 RNA, which is more efficient than that from the wild-type RNA, was poorly affected by eIF $4 \mathrm{G}$ cleavage showing a small inhibition only at high doses of L-protease (Fig. 3, lanes 1318). Interestingly, the relative ratio of expression of the three gag isoforms was not affected by this proteolytic event.

To further confirm these results and to evaluate any contribution of the cap from the wild-type HIV-2 RNA, we carried out translation assays using a competitive untreated rabbit reticulocyte lysate (Fig. 4). We have recently shown that this system faithfully recapitulates the synergistic effect of the cap and the poly(A) tail and the selective advantage of IRES dependent translation (Soto Rifo et al. 2007). Therefore, the untreated RRL was programmed with increasing amounts of the polyadenylated capped and uncapped HIV2 polyadenylated RNAs (Fig. 4, lanes 16). As observed in the nuclease treated lysate, translation of the uncapped and polyadenylated T7-WT was as efficient, if not more, as the capped version of the RNA, suggesting a poor contribution of the cap to overall Gag translation (Fig. 4, lanes 1-6). Furthermore, addition of the L protease also led to translation stimulation of the capped and polyadenylated T7-WT RNA, whereas endogenous globin and lipoxygenase translation was inhibited (Fig. 4, lanes 7-10). These experiments show that the synergy between the poly(A) tail and the cap exerts only a mild effect on overall translation from the HIV-2 wild-type genomic RNA, confirming the use of an internal initiation mechanism to produce the Gag polyproteins.

\section{The three IRES are functionally independent}

The next step was to determine whether each of the three AUGs could be used for initiation independently from each other. Therefore, the experimental approach consisted of the hybridization of short $2^{\prime}-O-$ methyloligoribonucleotides that were annealed to different regions of the HIV-2 mRNA molecule. Annealing of the oligos to the RNAs was tested by electrophoresis of RNAoligo duplexes on agarose gels (see Supplemental Fig. 2). As a control experiment to evaluate the effect of oligo hybridization on ribosomal scanning, a 2'-O-methyloligoribonucleotide complementary to the globin $5^{\prime}$-UTR was used and the resulting oligo-mRNA duplex was translated 
T7-WT HIV-2

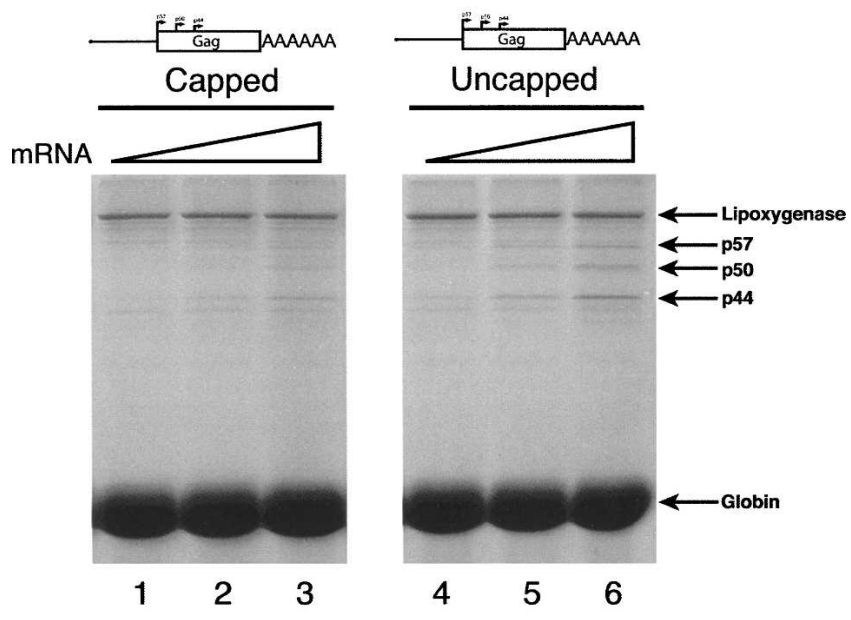

T7-WT HIV-2

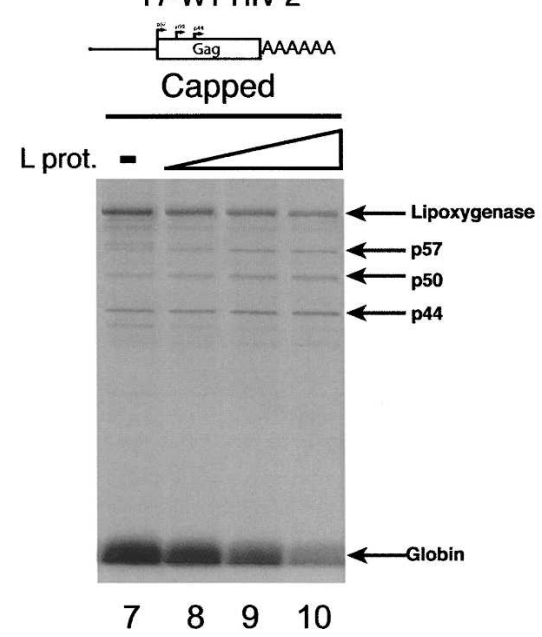

FIGURE 4. Translation of the HIV-2 T7-WT RNA in a competitive cap and poly-A dependent RRL. Translation of increasing amounts (50, 100, and $200 \mathrm{ng}$ ) of capped (lanes 1-3) and uncapped (lanes 4-6) poly-adenylated T7-WT RNA in the untreated RRL containing endogenous Globin and lipoxygenase mRNAs as indicated on the figure. Translation of $200 \mathrm{ng}$ of capped and poly-adenylated T7-WT RNA following preincubation of the untreated RRL for 10 min without (lane 7) or with $0.3 \mu \mathrm{L}$ (lane 8 ), or $0.7 \mu \mathrm{L}$ (lane 9), or with $1 \mu \mathrm{L}$ (lane 10) of in vitro produced FMDV L-protease. Translation products were resolved on a 13\% SDS-PAGE and submitted to autoradiography. Results are representative of at least three independent experiments.

in the RRL (Fig. 5, lanes 1-4). This resulted in a drastic inhibition of translation of the globin-LacZ RNA showing that the oligo-mRNA duplex was stable enough to arrest most of the scanning $40 \mathrm{~S}$ ribosomes. Interestingly, when a $2^{\prime}$-O-methyloligoribonucleotide was annealed to the primary binding site (PBS), which lies in the middle of the HIV-2 5'-UTR, we could only observe a marginal decrease in translation from the first AUG site with no effect on the downstream AUGs (Fig. 5, lanes 5-8). Hybridization of an oligo targeting the RNA region including the AUG1 initiation site resulted in the pronounced inhibition of translation at the proximal site but with virtually no effect on the expression of p50 and p44 which are synthesized from initiation at AUG2 and AUG3, respectively (Fig. 5, lanes 9-12). In a similar manner, hybridization of a $2^{\prime}-O-$ methyloligoribonucleotide at the second AUG site (AUG2) yielded some unexpected results (Fig. 5, lanes 13-16). First of all, it did not impair expression of p44 from the third AUG initiation site, suggesting that translation at AUG3 does not result from leaky scanning or read through from AUG2. Second, it can be clearly seen on the autoradiography that initiation occurred upstream of the AUG2 as judged by the slightly larger translation product made (Fig. 5, cf. lane 9 and lanes 10-12). This product (named p52) might result from translation initiation at a non-AUG codon since no AUG triplets (either in frame or out of frame) are located between AUG 1 and AUG2 and may correspond to an in-frame CUG codon that is present some 19 codons upstream of AUG2.

Taken together, these results indicate that there are three distinct and functionally independent internal entry sites located entirely in the gag coding region: IRES 1 lies downstream from its AUG entry site as described previously, the second IRES is located between AUG1 and AUG2, and the third IRES spans between AUG2 to AUG3. Interestingly, each of these three IRES has its own initiation site.

\section{The HIV-2 protease regulates the pattern of expression of Gag isoforms}

We next went on to investigate the molecular determinants that could control HIV-2 translation. In particular, it was of interest to study the effects of the viral HIV-2 protease on the translation of its cognate mRNA. This protease was previously shown to play a role in translation by cleaving the initiation factor eIF4G (Ventoso et al. 2001; Ohlmann et al. 2002). Such a proteolytic event yields an N-terminal fragment which contains the eIF4E binding site and a carboxyterminal domain identical to the L-protease generated eIF4G fragment except that it lacks a small 40 aa RNA binding domain previously described as being critical for ribosomal scanning (Prevot et al. 2003a). As a result, this C-terminal eIF4G fragment resulting from HIV-2 protease cleavage, which harbors the eIF4A and eIF3 binding site, is not competent to support ribosomal scanning. Thus, the RRL was pretreated with increasing amounts of the HIV-2 protease and then programmed with Globin-LacZ, EMCVLacZ, capped and uncapped wild-type HIV-2 (T7-WT HIV2 ), or the capped and uncapped leaderless HIV-2 (T7-AUG1 HIV-2) together with the Hepatitis C virus (HCV) mRNAs whose translation is not dependent on the integrity of eIF4G (Fig. 6). The cleavage of eIF4G was monitored by Western blot (see Supplemental Fig. 3). Addition of the recombinant HIV-2 protease did not affect HCV IRES translation (Fig. 6 , lanes 8,9$)$, indicating that no damage to the general 

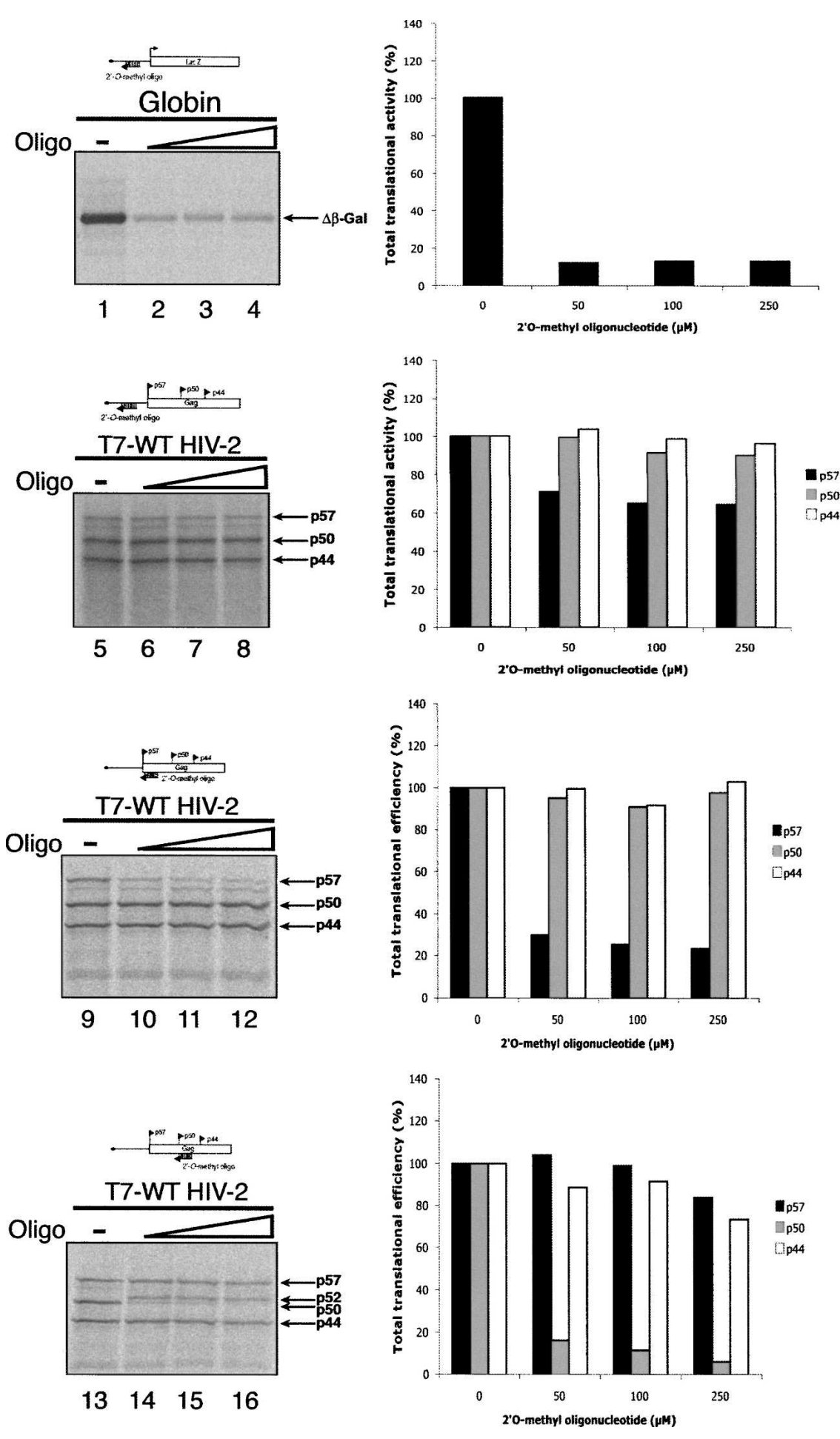

FIGURE 5. Three independent IRES control p57, p50, and p44 protein expression. Increasing concentrations (lane 1: $0 \mu \mathrm{M}$, lane 2: $50 \mu \mathrm{M}$, lane 3: $100 \mu \mathrm{M}$, and lane 4: $250 \mu \mathrm{M}$ ) of antisense $2^{\prime}$-O-methyloligoribonucleotides directed against the 5'-UTR of globin-LacZ (lanes 1-4), the primary binding site (PBS) of HIV-2 (lanes 5-8), the region encompassing AUG1 (9-12), or the region encompassing AUG2 (lanes 13-16) were hybridized to capped T7-WT RNA (200 $\mathrm{ng} / 10 \mu \mathrm{L}$ ) and the resulting oligo-RNA complex was translated in the RRL. Translation products were resolved on a $13 \%$ SDS-PAGE and submitted to autoradiography. The relative intensities of the bands were quantified using a storm 850 phosphoimager and expressed as arbitrary units presented on the right-hand side of each panel. The position of translation products is indicated on the figure. Results are representative of at least three independent experiments. translational machinery was caused by addition of the retroviral enzyme. As expected, expression of Globin-LacZ was virtually abolished (Fig. 6, lane 3) whereas translation of EMCV-IRES containing mRNA was affected to a lesser extent (Fig. 6, lane 6).

In contrast, production of $\mathrm{p} 57, \mathrm{p} 50$, and p44 Gag resulting from translation of T7-WT at the three AUG sites was only marginally impaired by addition of the HIV-2 enzyme (Fig. 6, lanes 11,12,14,15) whereas expression of the leaderless construct was inhibited by about $60 \%$ (Fig. 6, lanes 17,18,20,21). It is interesting to note that capping of the mRNAs (either T7-WT or the leaderless) did not change the pattern of protein expression. More importantly, and unlike the situation with the L-protease (see Figs. 3, 4), the pattern of expression of p57, p50, and p44 from the wild-type or the leaderless constructs was modified by addition of the HIV-2 protease. For instance, synthesis of p57 was inhibited from the WT RNA whereas production of $\mathrm{p} 50$ and $\mathrm{p} 44$ remained virtually similar to the control (Fig. 6, cf. lane 10 and lanes 11,12). In contrast, initiation at the third AUG site was almost abolished from the leaderless construct (Fig. 6, cf. lane 13 and lanes 14,15).

Taken together, these results show that expression of the HIV-2 protease has quantitative and qualitative impacts on the translation of its cognate mRNA and these effects are affected by the presence or absence of the $5^{\prime}$-UTR. This suggests that the level of expression of $\mathrm{p} 57, \mathrm{p} 50$, and $\mathrm{p} 44$ can vary according to changes in the physiological conditions used and that the 5'-UTR can affect the mechanism by which the ribosomes are recruited to the Gag coding region, thus explaining the different results obtained from the wild-type and the leaderless RNAs.

\section{The Gag polyprotein controls its own translation}

During the early steps of virus assembly, the Gag polyprotein plays a critical role in HIV-2 RNA packaging by binding to the mRNA, which allows the resulting 

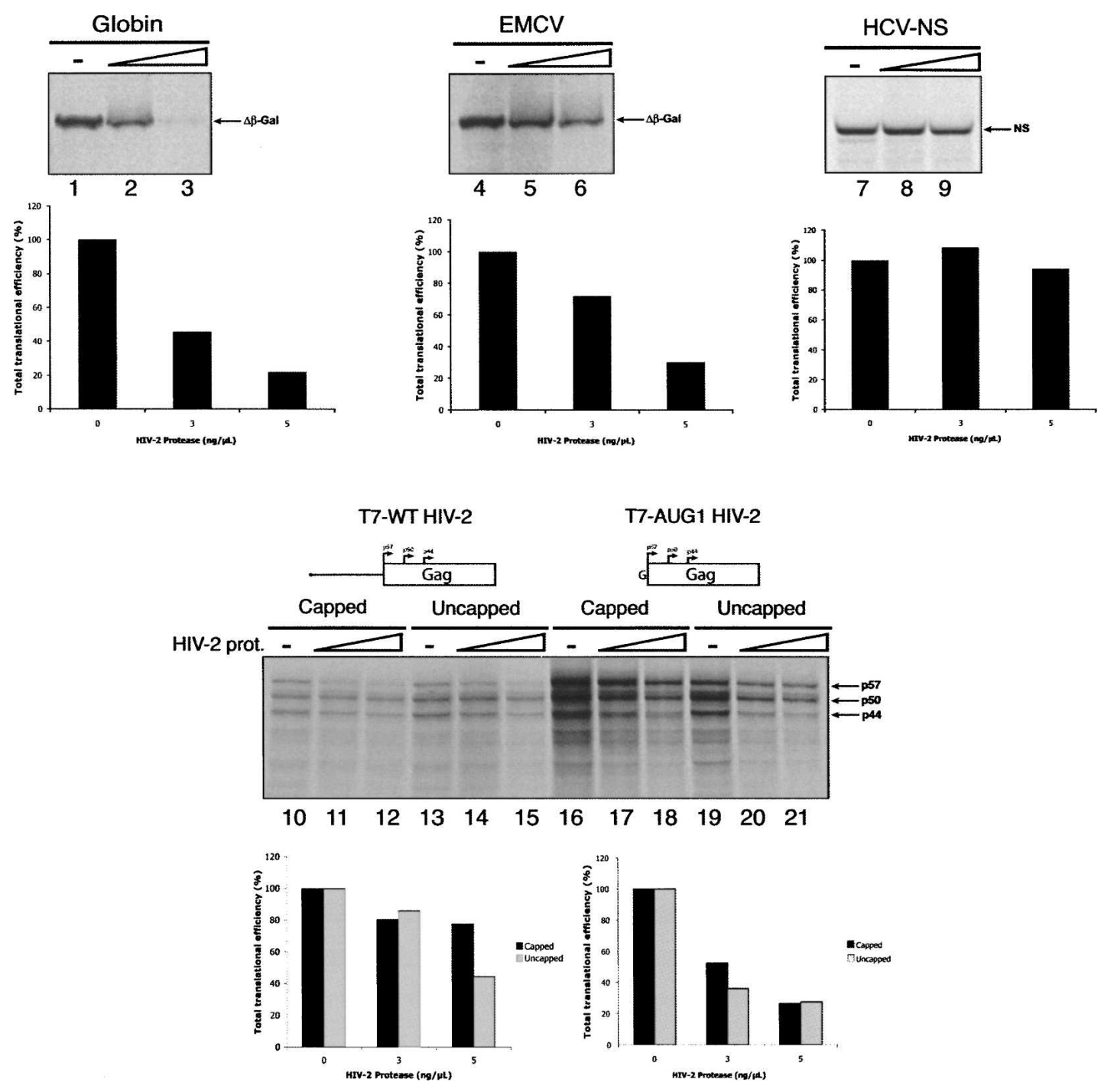

FIGURE 6. Addition of the recombinant HIV-2 protease modifies AUG codon selection. A RRL under full translation conditions was preincubated for $1 \mathrm{~h}$ without (lanes $1,4,7,10,13,16,19)$ or with $3 \mathrm{ng} / \mu \mathrm{L}$ (lanes $2,5,8,11,14,17,20$ ), or $5 \mathrm{ng} / \mu \mathrm{L}$ (lanes $3,6,9,12,15,18,21)$ of recombinant HIV-2 protease prior to addition of Palinavir $(10 \mu \mathrm{M})$. The following transcripts: Globin-LacZ (15 ng/10 $\mu \mathrm{L}), \mathrm{EMCV}-\mathrm{LacZ}$ (184 ng/ $10 \mu \mathrm{L}), \mathrm{HCV}$ NS $(100 \mathrm{ng} / 10 \mu \mathrm{L})$, T7-WT $(200 \mathrm{ng} / 10 \mu \mathrm{L})$, and T7-AUG1 $(35 \mathrm{ng} / 10 \mu \mathrm{L})$ were then translated as indicated on the figure and the resulting products resolved on a 10\% SDS-PAGE and submitted to autoradiography. The relative intensities of the bands were quantified using a storm 850 phosphoimager and expressed as arbitrary units presented at the bottom of each panel. T7-WT and T7-AUG1 overall translation was quantified by the addition of the activities of each of the Gag isoforms. Results are representative of at least three independent experiments.

ribonucleoprotein complex to be addressed to the plasma membrane (Kaye and Lever 1999). Interestingly, this process occurs at times when the genomic viral RNA is translated and, thus, most probably interferes with the process of protein synthesis. Curiously, the effect of the Gag polyprotein on translation has rarely been directly investigated by using in vitro translational assays. Thus, we have used recombinant HIV-1 Gag polyprotein that was added to translation assays programmed with different constructs including mRNAs in which LacZ production was driven by the Globin 5'-UTR or the EMCV IRES. The capped HIV-2 T7-WT and T7-AUG1 HIV-2 RNAs were also translated in the presence of increasing concentration of recombinant
Gag polyprotein. It should be noted that the HIV-1 Gag protein was shown to be able to bind to the HIV-2 RNA packaging signals with a similar affinity to the HIV-1 RNA signals (Kaye and Lever 1998); however this was confirmed in our experiment setting by Far Western and dot blot (data not shown). The relative molar ratio of Gag recombinant protein to RNA used ranged from 0 to 82 and the resulting Gag-RNA ribonucleoprotein complex was translated in the RRL under the conditions described in Materials and Methods. Results presented in Figure 5 show that, at low concentration, Globin-LacZ expression was only partly affected by the addition of Gag (Fig. 7, lanes 1-9). Translation driven by the EMCV IRES seemed to 

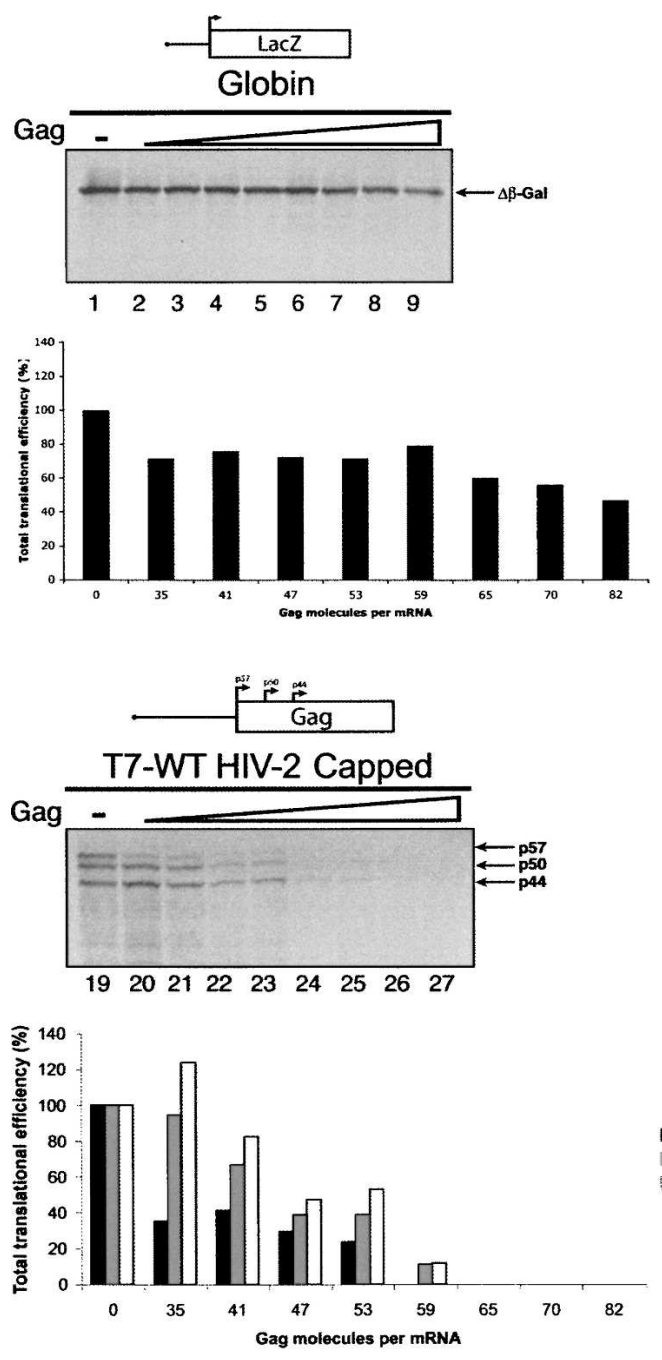

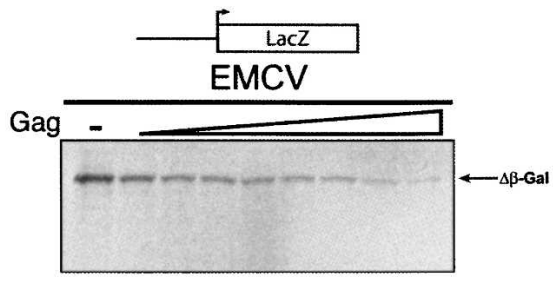

$10 \quad 11 \quad 12 \quad 13 \quad 14 \quad 1516 \quad 17 \quad 18$
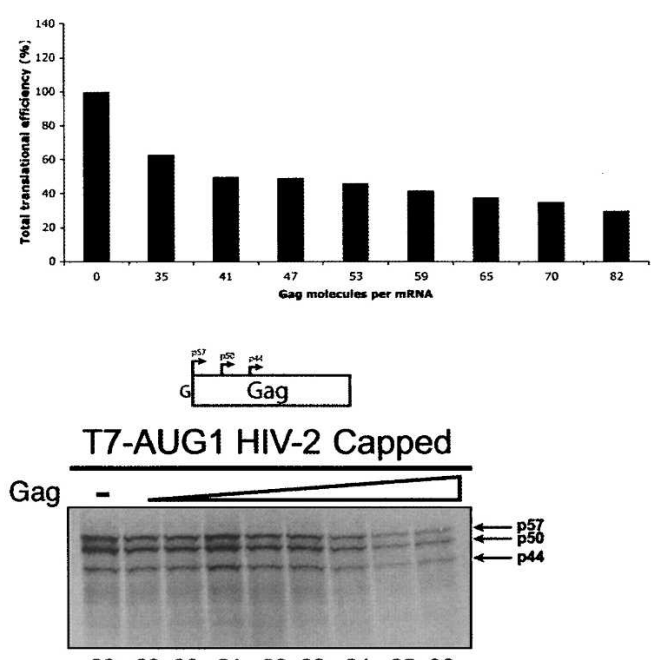

$\begin{array}{lllllllll}28 & 29 & 30 & 31 & 32 & 33 & 34 & 35 & 36\end{array}$

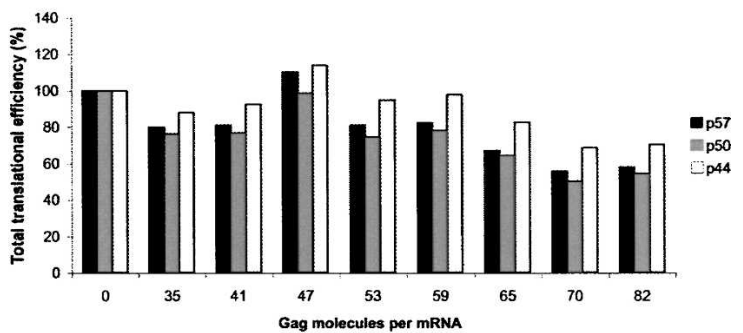

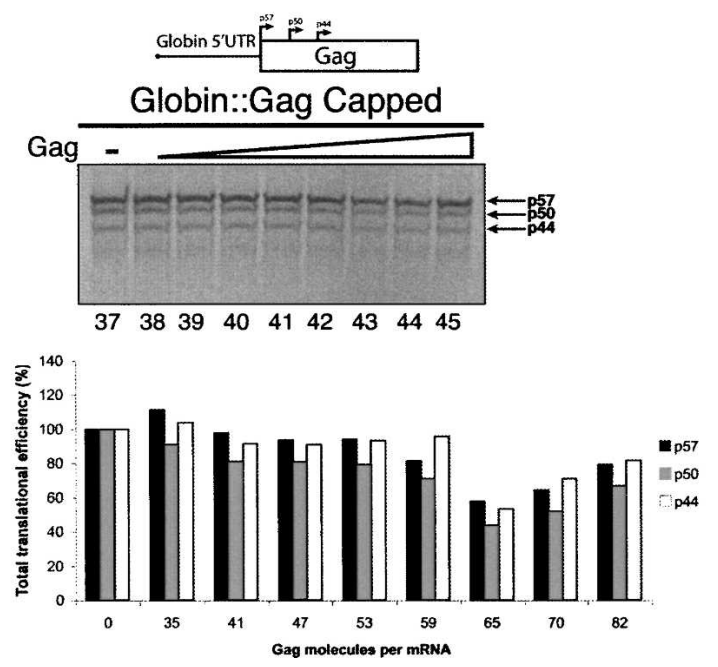

FIGURE 7. The Gag recombinant protein exerts a regulatory effect on the translation of the HIV-2 genomic RNA. Capped globin-LacZ (15 ng/10 $\mu \mathrm{L}$, lanes 1-9), capped EMCV-LacZ (184 ng/10 $\mu \mathrm{L}$, lanes 10-18), capped T7-WT (200 ng/10 $\mu \mathrm{L}$, lanes 19-27), capped T7-AUG1 (35 ng/10 $\mu \mathrm{L}$, lanes 28-36), and capped Globin::Gag (35 ng/10 $\mu \mathrm{L}$, lanes 37-45) RNAs were preincubated for $10 \mathrm{~min}$ at $30^{\circ} \mathrm{C}$ in the presence of increasing amounts of recombinant HIV-1 Gag protein ranging from 0 to 82 Gag molecules per RNA as indicated on the figure. The resulting Gag-RNAs complexes were then translated in the RRL for $45 \mathrm{~min}$ and the resulting products were resolved on a $13 \%$ SDS-PAGE and submitted to autoradiography. The relative intensities of the bands were quantified using a storm 850 phosphoimager and presented at the bottom of each panel. 
be more sensitive to the addition of the Gag polyprotein as production of $\beta$-Gal was gradually diminished in a dose dependent manner (Fig. 7, lanes 10-18).

However, in sharp contrast, translation of HIV-2 WT construct was markedly inhibited by preincubation of the mRNA even at low concentration of the recombinant Gag protein (Fig. 7, lanes 22,23) and translation was actually abolished at higher concentrations (Fig. 7, lanes 24 and above). Moreover, a significant change in the pattern of expression of the different Gag isoforms could also be observed at low concentrations of Gag added with expression of the longest p57 Gag isoform being more affected (Fig. 7, cf. lane 19 and lanes 20,21, and see the quantification panel). Interestingly, translation of the leaderless HIV-2 RNA (T7-AUG1) was also inhibited by recombinant Gag addition (Fig. 7, lanes 28-36), but this was not accompanied by drastic changes in the pattern of expression of the three Gag isoforms. Overall, translation from this construct was more resistant to Gag addition than the 5'-UTR containing wild type HIV-2 genomic RNA. It is noteworthy that the addition of a recombinant RNA binding protein such as the Lupus autoantigen $(\mathrm{La})$ failed to induce any quantitative or qualitative variation on the expression of Gag isoforms ruling out any nonspecific effect (data not shown). Furthermore, translation of a chimeric RNA which contains the 5'-UTR of human $\beta$ globin driving the synthesis of the HIV-2 Gag coding region was also monitored (Globin::Gag). Interestingly this showed a translational profile which was similar to that of the globin-LacZ RNA and the leaderless HIV-2 RNA (Fig. 7, lanes 37-45). In fact, translation from this RNA was not really sensitive to addition of the recombinant Gag protein and no significant change in the use of initiation codons could be observed. These experiments suggest that Gag polyprotein plays a regulatory role in the translation of its cognate mRNA and this regulation appears to be exerted via an interaction with the viral $5^{\prime}$-UTR.

This work and previous data have shown that translation of the HIV-2 genomic RNA can take place in the complete absence of $5^{\prime}$-UTR from a leaderless construct (Herbreteau et al. 2005). However, results presented herein suggest that the $5^{\prime}$-UTR may exert an inhibitory role in the presence of the Gag polyprotein by acting as a dock for Gag recruitment near the AUG1 codon, thus inhibiting p57 translation. Indeed, the 5'-UTR of lentiviruses harbors RNA signals that are the preferential Gag binding site for RNA packaging in the course of viral assembly. To investigate the role of the $5^{\prime}$-UTR-Gag interactions in the process of translation initiation, two different RNA competitors were independently preincubated with the Gag protein at a high protein to RNA ratio (83:1). These RNA competitors correspond to the whole 546-nt-long HIV-2 5 '-UTR (from +1 to nucleotide 546) or a 546-nt-long unspecific RNA sequence taken from the unrelated $\beta$ Galactosidase ( $\beta-\mathrm{Gal})$ gene. These RNA competitors were added in a 1:1 molar ratio with the T7-WT and T7-AUG1 RNAs.

The results presented in Figure 8 show that translation of T7-WT and T7-AUG1 drive the synthesis of Gag p57, p50, and p44 together with another intermediate isoform that was observed previously (Fig. 5; data not shown) and which might result from alternative translation initiation at a nonAUG codon located between AUG1 and AUG2. Addition of an excess amount of recombinant Gag protein $(83$ molar excess over the RNA concentration) results in the complete inhibition of protein synthesis from both the wild type (T7WT) and the leaderless (T7-AUG1) RNAs (Fig. 8, lanes 2,8). Interestingly, in the case of the wild-type construct, addition of the $\beta$-Gal unspecific RNA competitor was able to rescue translation of the p50 and p44 isoforms but not that of the p57 longest protein (Fig. 8, lane 4). The expression of the longest Gag isoforms was only completely restored when the HIV-2 5'-UTR was used as a competitor RNA (Fig. 8, lane 6). Interestingly, addition of the $5^{\prime}$-UTR or the unspecific RNA competitor was of similar efficiency to fully restore translation from the leaderless construct (Fig. 8, T7-AUG1
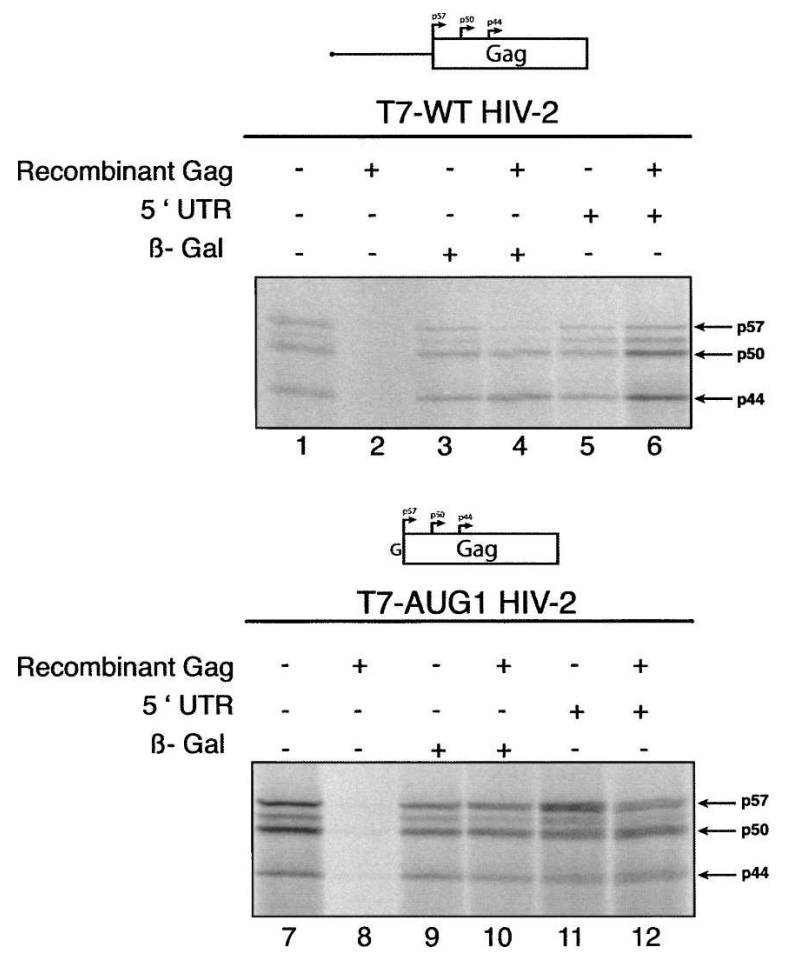

FIGURE 8. The $5^{\prime}$-UTR of the HIV- 2 genomic RNA act as a dock for the Gag polyprotein thus having an inhibitory effect on its own translation. RRL under full translational conditions was incubated in the absence (lanes 1,7 ) or presence of a large excess of recombinant Gag protein (all other lanes, 82:1 protein to RNA ratio). Uncapped T7-WT $(15 \mathrm{ng} / \mu \mathrm{L})$ and T7-AUG1 $(5 \mathrm{ng} / \mu \mathrm{L})$ RNAs were translated in the absence (lanes 2,8 ) or presence of the HIV-2 $5^{\prime}$-UTR added in trans (lanes $5,6,11,12$ ) or an unspecific $\beta$-Gal RNA (lanes 3,4,9,10). Samples were processed on a $12 \%$ SDS-PAGE and submitted to autoradiography. 
HIV-2, lanes 10,12). Taken together, these data suggest that the Gag polyprotein regulates translation of its cognate RNA by binding to its $5^{\prime}$-UTR. This results in the overall modulation of translation efficiency together with changes in the selection of the AUG initiation site.

\section{DISCUSSION}

We have recently demonstrated that translation of the HIV2 genomic RNA drives the synthesis of Gag p57 and two isoforms named Gag p50 and Gag p44 that are initiated at three distinct AUG codons. This mechanism is rendered possible by the use of an IRES in the coding region which has the unique ability to recruit ribosome upstream of its core domain (Herbreteau et al. 2005). As a result, translation of the HIV-2 genomic RNA can occur in the complete absence of $5^{\prime}$-UTR from an RNA that commences directly at the AUG initiation codon.

In this article, we extend this study further and show that the three distinct Gag isoforms are produced by three independent IRES both in vitro and ex vivo. The first IRES is located downstream from the authentic AUG1 initiation site as previously shown (Herbreteau et al. 2005). The second IRES element is located between the first and the second AUG, between positions nucleotides 662 and 746 . The last and third IRES element maps between positions nucleotides 748 and 899, which corresponds to the RNA region located between AUG2 and AUG3 (Figs. 1, 2).

To ensure that translation at the three distinct AUG sites was the result of internal initiation and not due to leaky ribosomal scanning from the first AUG codon, the Lprotease from FMDV was utilized to inhibit cap-dependent translation. Upon addition of the viral enzyme, expression from the three AUG sites was enhanced indicating the use of a cap-independent mechanism (Fig. 3). Interestingly, this could be observed whether the mRNAs were capped or not, showing that the cap structure plays only little role in this process. This result was further confirmed by the use of a synergistic competitive reticulocyte lysate (Soto Rifo et al. 2007) in which the addition of a cap structure to the polyadenylated wild-type RNA showed no effect on overall Gag translation (Fig. 4). The use of antisense 2' $O$-methyloligoribonucleotides that block ribosomal scanning also yielded some interesting results (Fig. 5). First of all, it showed that annealing of an antisense oligo to the PBS in the middle of the HIV-2 5'-untranslated region only had a mild effect on protein production, confirming that the presence of the gag coding region is both necessary and sufficient for translation (Fig. 5, lanes 5-8). Second, hybridization of the oligos at different positions within the gag coding region suggests that access at each of the AUG initiation sites occurs in an independent manner (Fig. 5, lanes 9-16).

We then went on to investigate the viral molecular determinants that can control HIV-2 IRES-driven translation. A first candidate was the HIV-2 protease as the latter was shown to play a role in the control of translation by cleaving the initiation factor eIF4G (Prevot et al. 2003b). This cleavage was shown to inhibit ribosomal scanning without affecting $43 \mathrm{~S}$ binding to the mRNA (Prevot et al. 2003b). Treatment of the rabbit reticulocyte lysate with the HIV-2 protease ultimately resulted in the shutoff of Globin-LacZ mRNA translation, inhibition of both EMCV and the leaderless HIV-2 constructs, but had virtually no effect on the wild-type HIV-2 genomic RNA (Fig. 6). More importantly, changes in the relative utilization of the AUG initiation codons could be observed. Initiation at the proximal site on the wild-type HIV-2 RNA was inhibited without affecting expression from the two downstream AUG codons. This result strongly suggests that initiation at AUG1 could involve some ribosomal scanning whereas initiation from AUG2 and AUG3 would occur by direct ribosomal binding to these sites. These results suggest that the pattern of expression of the HIV-2 Gag isoforms can be affected independently from each other and that the presence or absence of the 5'-UTR plays a role in this process. These differences observed in the absence of the $5^{\prime}$-UTR could be explained by the fact that leaderless mRNAs have been shown to be able to recruit $80 \mathrm{~S}$ ribosomes directly to the start codon (Andreev et al. 2006). Interestingly, the cleavage of eIF4G by the FMDV-L-protease did not modify the relative ratio of Gag isoform synthesis arguing for a very specific influence of the enzyme on its cognate genomic RNA (Fig. 3).

In view of these data, it was of interest to investigate whether other viral proteins could modulate translation of the HIV-2 genomic RNA. An obvious candidate was the Gag polyprotein itself, since the latter is involved in the packaging of the HIV-2 genomic RNA by binding structured RNA stem-loops that lie within the 5'-UTR (Kaye and Lever 1998; Griffin et al. 2001) and could interfere with translation. Addition of increasing concentrations of recombinant Gag did not seriously affect translation driven by the globin $5^{\prime}$-UTR (Fig. 7). However, it had a very strong impact on the WT HIV-2 construct by sharply inhibiting protein synthesis at a relatively low Gag concentration and influencing the relative ratio of utilization of the AUG start sites (Fig. 7). In fact, initiation at the AUG1 proximal site was drastically impaired whereas translation at the second and third AUG codons remained unaffected until a high concentration of Gag was used. Interestingly, inhibition of WT HIV-2 translation was sudden and drastic when a certain concentration of Gag was added to the RRL (Fig. 7, lanes 23,24). In contrast, expression of p57, p50, and p44 from the HIV-2 leaderless construct was gradually inhibited. Such a situation also occurred when the EMCV IRES was used (Fig. 7, lanes 10-18) with a 
gradual impairment of protein production. However, translation of Gag isoforms from the chimeric RNA (Globin::Gag) showed no significant inhibition upon recombinant Gag addition, suggesting that the HIV-2 5'UTR plays an important role in this inhibition process.

Thus, we postulated that the different behavior of these constructs to Gag addition may reveal cooperative binding of the polyprotein to the packaging signals located within the $5^{\prime}$-UTR. This was investigated by adding in trans the HIV-2 $5^{\prime}$-UTR or an unrelated $\beta$-Gal RNA sequence to the RRL supplemented with a relatively large excess of Gag polyprotein (Fig. 8). Trans-addition of either the viral leader or an unrelated $\beta$-Gal sequence resulted in the rescue of expression of p50 and p44 isoforms from both the WT and leaderless HIV-2 constructs. However, translation at the proximal AUG site (AUG1) could only be restored by the trans-addition of the viral leader on its cognate genomic RNA.

In summary, data presented herein show that both the HIV-2 protease and the viral polyprotein can modulate translation of the genomic RNA in such a way that initiation at the AUG1 proximal site becomes rapidly inhibited (Figs. 6, 7) upon slight increase in protein concentration whereas production of $\mathrm{p} 50$ and p44 continues until a relatively high amount of Gag is added. Since the presence of IRES elements driving synthesis of truncated Gag isoforms has become a conserved feature of the lentiviral family as it has now been characterized within the HIV-1 (Buck et al. 2001), SIV (Nicholson et al. 2006), and HIV-2 (Herbreteau et al. 2005) genomic RNAs, this suggests that initiation from the coding region may be a way to increase the production of the $\mathrm{CA}, \mathrm{NC}$, and $\mathrm{p} 6$ proteins. Based on these data, we propose a model for HIV-2 translation in which the ribosomes initially reach the proximal AUG1 site to produce the full-length polyprotein. While the latter is being synthesized, it binds preferentially to its cognate $5^{\prime}$ UTR creating a scaffold of RNA-Gag complex which progressively occludes the accessibility of the $5^{\prime}$-UTR for ribosomes by steric hindrance (our results; see also (Kaye and Lever 1998; Griffin et al. 2001). At this stage, preferential production of the Gag truncated isoforms is taking place from ribosomal entry at the internal AUG codons, ensuring that viral protein production continues during the initial steps of viral assembly. It is noteworthy that these Nt-truncated Gag isoforms have the ability to interact with the full length p57 Gag polyprotein to assemble in the form of virus-like particles at the plasma membrane (Herbreteau et al. 2005). At a later stage, when full length Gag and the truncated isoforms have been produced in a sufficient amount, translation of the HIV-2 genomic RNA is stopped by the binding and accumulation of these proteins on its cognate messenger. Such a mechanism could discriminate between the end of viral protein synthesis and the beginning of viral packaging and assembly.

\section{MATERIALS AND METHODS}

\section{Protease, antibodies, recombinant Gag protein, and other reagents}

The L-protease from FMDV was generated by in vitro translation as described previously (Prevot et al. 2003a). The recombinant HIV-1 Gag protein was prepared as described (Datta et al. 2007) and solubilized in a buffer containing $20 \mathrm{mM}$ Tris $\mathrm{HCl} \mathrm{pH}$ 7.4, 0.5 $\mathrm{M} \mathrm{NaCl}, 5 \mathrm{mM}$ DTT, $1 \mathrm{mM}$ PMSF, and a protease inhibitors cocktail (Roche Inc.). These conditions are taken in consideration for translation experiments performed in the presence of this protein to maintain equivalent levels of salt, $\mathrm{pH}$, DTT, and antiprotease in each reaction tube.

\section{Hybridization of 2'-O-methyloligoribonucleotides}

Antisense 2'-O-methyloligoribonucleotides spanning positions nucleotides 306-327 (antisense to the PBS), nucleotides 548-566 (antisense to AUG1), nucleotides 747-765 (antisense to AUG2) of the HIV-2 RNA were annealed to RNA in $20 \mathrm{mM}$ Hepes/ $\mathrm{KCl}(\mathrm{pH}$ 7.6) and $100 \mathrm{mM} \mathrm{KCl}$ for $3 \mathrm{~min}$ at $65^{\circ} \mathrm{C}$ followed by $20 \mathrm{~min}$ incubation at room temperature.

An antisense 2'-O-methyloligoribonucleotide spanning positions nucleotides 22-42 (antisense to Globin 5'-UTR) was annealed to Globin-LacZ as described above and used as a control for measuring ribosomal scanning inhibition.

\section{Plasmid construction}

Standard procedures were used for plasmid DNA construction, purification, and linearization. Details of the constructs used in this study are given below.

pBi-AUG1, pBi-AUG2, pBi-AUG3, pBi-AUG1-3, pBi 662-AUG3, and $p B i$ 748-AUG3

Sequences of the HIV-2 from the +1 transcription start site (R) up to the AUG start codon at position 548 (pBi-AUG1), or from the +1 up to the AUG at position 746 (pBi-AUG2), or from the +1 up to the AUG at position 899 (pBi-AUG3), or from position 546 to position 899 (pBi-AUG1-3), or from position 662 to position 899 (pBi-662-AUG3), or from position 748 to position 899 (pBi-748-AUG3) were amplified by PCR, digested by NheI (PCR added restriction site) and inserted into pBi-NL (described in Ronfort et al. 2004) previously digested by NheI. pEMCV-LacZ and pHCV-NS have been previously described (Prevot et al. 2003b). pGlobin-LacZ contains the 5'-UTR of rabbit $\beta$ Globin (52 nt in length) which drives translation of the LacZ gene (kindly donated by Dr. B. Sargueil, CNRS, Gif sur Yvette, France). For Globin::Gag, the sequence of T7 promoter followed by the globin 5'-UTR was amplified by PCR and digested by XbaI and NcoI (PCR added restriction site). The digested sequence was then inserted into the pcDNA3.1 (Invitrogene) vector previously digested by $\mathrm{XbaI}$ and NcoI. The sequence of the Gag coding region was amplified by PCR and digested by NcoI and AflII (PCR added restriction site). The digested sequence was then inserted into the pcDNA3.1 vector, containing the $5^{\prime}$-UTR of globin, previously digested by NcoI and AflII. 


\section{Ricci et al.}

\section{pFR vector}

The firefly luciferase coding region (amplified by PCR) containing the restriction site for BamHI (at the $5^{\prime}$ end) and a 50-nt polylinker (at the $3^{\prime}$ end, containing restriction sites for AflII, AflIII, AccI, KpnI, PstI, PmlI, SpeI, and SalI) followed by a BglII restriction site, was inserted into the pRenilla vector (described in Soto Rifo et al. 2007) previously digested with BamHI. EcoRI and EcoRV restriction sites located within the firefly luciferase coding region were then mutated using the QuickChange site-directed mutagenesis kit (Stratagene).

pFR-NoIRES, pFR-AUG3, pFR-AUG1-3, pFR-662-AUG3, and $p F R-748-A \cup G 3$

Sequences of the HIV-2 from position 546 to position 899 (pFRAUG1-3), or from position 662 to position 899 (pFR-662-AUG3), or from position 748 to position 899 (pFR-748-AUG3) were amplified by PCR, digested by SalI and BamHI (PCR added restriction site) and inserted into the $\mathrm{pFR}$ vector previously digested by SalI and BamHI.

\section{In vitro transcription and translation}

The Neo-Lac Z plasmid DNAs were linearized at the SspI site thus producing a $46 \mathrm{kDa}$ truncated version of $\beta$-Galactosidase. The Globine::Gag pcDNA3.1 plasmid DNA was linearized at the EcoRI site. The pFR plasmid was linearized at the EcoRI just after the synthetic poly(A) tail. RNAs were synthesized in vitro as previously described (Prevot et al. 2003b). The integrity of the RNAs was checked by electrophoresis on nondenaturing agarose gels and their concentration was quantified by spectrophotometry at $260 \mathrm{~nm}$ using a Nanodrop (Nanodrop Technologies).

In vitro transcribed RNAs were translated in $10 \mu \mathrm{L}$ of either the Flexi Rabbit Reticulocyte System (Promega Co.) or the supplemented untreated RRL 50\% (v/v) each (as described in Soto Rifo et al. 2007) in the presence of $75 \mathrm{mM} \mathrm{KCl}, 2.5 \mathrm{mM} \mathrm{MgCl}_{2}$, $20 \mu \mathrm{M}$ of each amino acid (minus methionine), and $0.6 \mathrm{mCi} / \mathrm{mL}$ of $\left[{ }^{35} \mathrm{~S}\right]$-methionine (GE Healthcare Life Sciences). Translation was carried out for $30 \mathrm{~min}$ at $30^{\circ} \mathrm{C}$ and stopped by the addition of $2 \times$ SDS-loading buffer. Translation products were resolved by $15 \%$ SDS-PAGE, gels were dried and subjected to autoradiography using Biomax films (Eastman Kodak Co.). Densitometric analyses were performed by phosphorimaging with a Storm 850 PhosphorImager.

\section{T7 RNA polymerase transcription of PCR DNA fragments}

The DNA sequence corresponding to the coding region of HIV-2 gag (pROD10), were amplified by PCR using a $3^{\prime}$ oligonucleotide starting at the end of the HIV-2 gag, and a $5^{\prime}$ to $3^{\prime}$ sense oligonucleotide starting with the $\mathrm{T} 7$ promoter sequence and complementary to the +1 region of the $5^{\prime}$-UTR, or to the AUG1 start codon, to generate T7-WT and T7-AUG1, respectively. Following purification of the PCR fragments, in vitro transcription using the T7 bacteriophage polymerase was conducted as described above. It should be noted that due to the much higher translational efficiency of the leaderless construct as shown previously (Herbreteau et al. 2005), the latter was utilized at a lower RNA concentration than the wild-type HIV-2 construct.

\section{RNA transfection}

HeLa cells were transfected using the TransIT RNA transfection kit (Mirus Bio Corporation) as described (Dieterich et al. 2007).

\section{Measure of luciferase activities from HeLa cells transfected with bicistronics RNAs}

HeLa cells were plated at a density of 150,000 cells per well (24 well plate) and transfected with $100 \mathrm{ng}$ of the p2A RNA coding for the protease from poliovirus (Ronfort et al. 2004). After $2 \mathrm{~h}$, the cells were transfected again with 0.156 pmol of the corresponding capped and polyadenylated bicistronic RNA. Three hours post transfection, cells were lysed and luciferase activities were measured using the dual reporter luciferase assay (Promega) on a Veritas luminometer (Turner Biosystems) following the manufacturer's protocol.

\section{SUPPLEMENTAL DATA}

Supplemental material can be found at http://www.rnajournal.org.

\section{ACKNOWLEDGMENTS}

The following reagents were obtained through the AIDS Research and Reference Reagent Program, NIAID, NIH: HIV-2 PR. from Bret Shirley and Mr. Michael Cappola, Boehringer Ingelheim Pharmaceuticals, Inc. We thank Dr. Bruno Sargueil (CNRS, Gif sur Yvette, France) for kindly donating the pglobin plasmid, Dr. S. J. Morley for donating eIF4G antibodies. The research of S.A.K.D and A.R. was supported in part by the intramural research program of the NIH, National Cancer Institute. A.S. was funded by the Friedrich-Naumann-Stiftung. C.H.H. was funded by MENRT and FRM grants; E.P.R. is funded by a MENRT grant and work in our laboratory is supported by grants from ANR, ANRS, INSERM, ACI, and TRIOH from EC sixth PCRD.

Received September 5, 2007; accepted March 11, 2008.

\section{REFERENCES}

Andreev, D.E., Terenin, I.M., Dunaevsky, Y.E., Dmitriev, S.E., and Shatsky, I.N. 2006. A leaderless mRNA can bind to mammalian $80 \mathrm{~S}$ ribosomes and direct polypeptide synthesis in the absence of translation initiation factors. Mol. Cell. Biol. 26: 31643169.

Balvay, L., Lastra, M.L., Sargueil, B., Darlix, J.L., and Ohlmann, T. 2007. Translational control of retroviruses. Nat. Rev. Microbiol. 5: $128-140$.

Bock, P.J. and Markovitz, D.M. 2001. Infection with HIV-2. AIDS (Suppl 5) 15: S35-S45.

Bonnal, S., Boutonnet, C., Prado-Lourenco, L., and Vagner, S. 2003. IRESdb: The internal ribosome entry site database. Nucleic Acids Res. 31: 427-428.

Brasey, A., Lopez-Lastra, M., Ohlmann, T., Beerens, N., Berkhout, B., Darlix, J.L., and Sonenberg, N. 2003. The leader of human immunodeficiency virus type 1 genomic RNA harbors an internal 
ribosome entry segment that is active during the $\mathrm{G} 2 / \mathrm{M}$ phase of the cell cycle. J. Virol. 77: 3939-3949.

Buck, C.B., Shen, X., Egan, M.A., Pierson, T.C., Walker, C.M., and Siliciano, R.F. 2001. The human immunodeficiency virus type 1 gag gene encodes an internal ribosome entry site. J. Virol. 75: 181-191.

Butsch, M. and Boris-Lawrie, K. 2002. Destiny of unspliced retroviral RNA: Ribosome and/or virion? J. Virol. 76: 3089-3094.

Camerini, V., Decimo, D., Balvay, L., Pistello, M., Bendinelli, M., Darlix, J.L., and Ohlmann, T. 2008. A "dormant" IRES controls translation of the feline immunodeficiency virus (FIV). J. Virol. 82: 3574-3883.

Datta, S.A., Curtis, J.E., Ratcliff, W., Clark, P.K., Crist, R.M., Lebowitz, J., Krueger, S., and Rein, A. 2007. Conformation of the HIV-1 Gag protein in solution. J. Mol. Biol. 365: 812-824.

Dieterich, K., Soto Rifo, R., Faure, A.K., Hennebicq, S., Ben Amar, B., Zahi, M., Perrin, J., Martinez, D., Sele, B., Jouk, P.S., et al. 2007. Homozygous mutation of AURKC yields large-headed polyploid spermatozoa and causes male infertility. Nat. Genet. 39: 661-665.

Gale Jr., M., Tan, S.L., and Katze, M.G. 2000. Translational control of viral gene expression in eukaryotes. Microbiol. Mol. Biol. Rev. 64: 239-280.

Gingras, A.C., Raught, B., and Sonenberg, N. 1999. eIF4 initiation factors: Effectors of mRNA recruitment to ribosomes and regulators of translation. Annu. Rev. Biochem. 68: 913-963.

Griffin, S.D., Allen, J.F., and Lever, A.M. 2001. The major human immunodeficiency virus type 2 (HIV-2) packaging signal is present on all HIV-2 RNA species: Cotranslational RNA encapsidation and limitation of Gag protein confer specificity. J. Virol. 75: 12058-12069.

Herbreteau, C.H., Weill, L., Decimo, D., Prevot, D., Darlix, J.L., Sargueil, B., and Ohlmann, T. 2005. HIV-2 genomic RNA contains a novel type of IRES located downstream of its initiation codon. Nat. Struct. Mol. Biol. 12: 1001-1007.

Jackson, R.J., Hunt, S.L., Gibbs, C.L., and Kaminski, A. 1994. Internal initiation of translation of picornavirus RNAs. Mol. Biol. Rep. 19: 147-159.

Jang, S.K., Krausslich, H.G., Nicklin, M.J., Duke, G.M., Palmenberg, A.C., and Wimmer, E. 1988. A segment of the $5^{\prime}$ nontranslated region of encephalomyocarditis virus RNA directs internal entry of ribosomes during in vitro translation. J. Virol. 62: 2636-2643.

Kaye, J.F. and Lever, A.M. 1998. Nonreciprocal packaging of human immunodeficiency virus type 1 and type 2 RNA: A possible role for the $\mathrm{p} 2$ domain of Gag in RNA encapsidation. J. Virol. 72: 58775885.

Kaye, J.F. and Lever, A.M. 1999. Human immunodeficiency virus types 1 and 2 differ in the predominant mechanism used for selection of genomic RNA for encapsidation. J. Virol. 73: 3023-3031.

Kozak, M. 1989. The scanning model for translation: An update. J. Cell Biol. 108: 229-241.

Lemey, P., Pybus, O.G., Wang, B., Saksena, N.K., Salemi, M., and Vandamme, A.M. 2003. Tracing the origin and history of the HIV2 epidemic. Proc. Natl. Acad. Sci. 100: 6588-6592.

Nicholson, M.G., Rue, S.M., Clements, J.E., and Barber, S.A. 2006. An internal ribosome entry site promotes translation of a novel SIV Pr55(Gag) isoform. Virology 349: 325-334.

Ohlmann, T., Pain, V.M., Wood, W., Rau, M., and Morley, S.J. 1997. The proteolytic cleavage of eukaryotic initiation factor (eIF) $4 \mathrm{G}$ is prevented by eIF4E binding protein (PHAS-I; 4E-BP1) in the reticulocyte lysate. $E M B O J$. 16: 844-855.
Ohlmann, T., Lopez-Lastra, M., and Darlix, J.L. 2000. An internal ribosome entry segment promotes translation of the simian immunodeficiency virus genomic RNA. J. Biol. Chem. 275: 11899-11906.

Ohlmann, T., Prevot, D., Decimo, D., Roux, F., Garin, J., Morley, S.J., and Darlix, J.L. 2002. In vitro cleavage of eIF4GI but not eIF4GII by HIV-1 protease and its effects on translation in the rabbit reticulocyte lysate system. J. Mol. Biol. 318: 9-20.

Otto, G.A. and Puglisi, J.D. 2004. The pathway of HCV IRESmediated translation initiation. Cell 119: 369-380.

Pelletier, J. and Sonenberg, N. 1988. Internal initiation of translation of eukaryotic mRNA directed by a sequence derived from poliovirus RNA. Nature 334: 320-325.

Prevot, D., Darlix, J.L., and Ohlmann, T. 2003a. Conducting the initiation of protein synthesis: The role of eIF4G. Biol. Cell. 95: 141-156.

Prevot, D., Decimo, D., Herbreteau, C.H., Roux, F., Garin, J., Darlix, J.L., and Ohlmann, T. 2003b. Characterization of a novel RNA-binding region of eIF4GI critical for ribosomal scanning. EMBO J. 22: 1909-1921.

Reeves, J.D. and Doms, R.W. 2002. Human immunodeficiency virus type 2. J. Gen. Virol. 83: 1253-1265.

Ronfort, C., De Breyne, S., Sandrin, V., Darlix, J.L., and Ohlmann, T. 2004. Characterization of two distinct RNA domains that regulate translation of the Drosophila gypsy retroelement. RNA 10: 504515.

Soto Rifo, R., Ricci, E.P., Decimo, D., Moncorge, O., and Ohlmann, T. 2007. Back to basics: The untreated rabbit reticulocyte lysate as a competitive system to recapitulate cap/poly(A) synergy and the selective advantage of IRES-driven translation. Nucleic Acids Res. 35: e121.

Spahn, C.M., Jan, E., Mulder, A., Grassucci, R.A., Sarnow, P., and Frank, J. 2004. Cryo-EM visualization of a viral internal ribosome entry site bound to human ribosomes: The IRES functions as an RNA-based translation factor. Cell 118: 465-475.

Stoneley, M. and Willis, A.E. 2004. Cellular internal ribosome entry segments: Structures, trans-acting factors and regulation of gene expression. Oncogene 23: 3200-3207.

Vagner, S., Galy, B., and Pyronnet, S. 2001. Irresistible IRES, Attracting the translation machinery to internal ribosome entry sites. EMBO Rep. 2: 893-898.

Ventoso, I., Blanco, R., Perales, C., and Carrasco, L. 2001. HIV-1 protease cleaves eukaryotic initiation factor $4 \mathrm{G}$ and inhibits capdependent translation. Proc. Natl. Acad. Sci. 23: 23.

Waysbort, A., Bonnal, S., Audigier, S., Esteve, J., and Prats, A. 2001. Pyrimidine tract binding protein and La autoantigen interact differently with the $5^{\prime}$ untranslated regions of lentiviruses and oncoretrovirus mRNAs. FEBS Lett. 490: 54-58.

Yaman, I., Fernandez, J., Liu, H., Caprara, M., Komar, A.A., Koromilas, A.E., Zhou, L., Snider, M.D., Scheuner, D., Kaufman, R.J., et al. 2003. The zipper model of translational control: A small upstream ORF is the switch that controls structural remodeling of an mRNA leader. Cell 113: 519-531.

Ziegler, E., Borman, A.M., Deliat, F.G., Liebig, H.D., Jugovic, D., Kean, K.M., Skern, T., and Kuechler, E. 1995. Picornavirus 2A proteinase-mediated stimulation of internal initiation of translation is dependent on enzymatic activity and the cleavage products of cellular proteins. Virology 213: 549-557. 

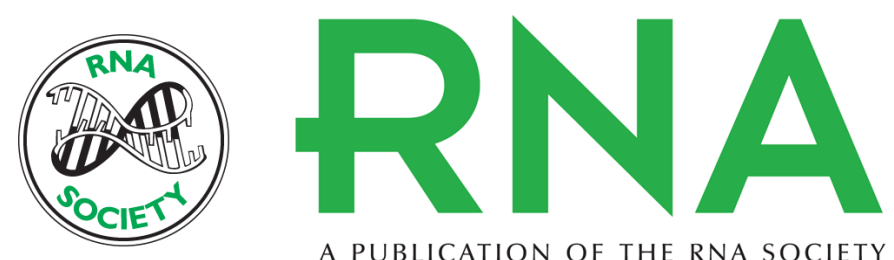

A PUBLICATION OF THE RNA SOCIETY

\section{In vitro expression of the HIV-2 genomic RNA is controlled by three distinct internal ribosome entry segments that are regulated by the HIV protease and the Gag polyprotein}

Emiliano P. Ricci, Cécile H. Herbreteau, Didier Decimo, et al.

RNA 2008 14: 1443-1455

Supplemental http://rnajournal.cshlp.org/content/suppl/2008/05/22/rna.813608.DC1
Material

References This article cites 38 articles, 16 of which can be accessed free at:

http://rnajournal.cshlp.org/content/14/7/1443.full.html\#ref-list-1

License

Email Alerting Receive free email alerts when new articles cite this article - sign up in the box at the Service top right corner of the article or click here. 